\title{
A Partial Flip, A Whole Transformation: Redesigning Sophomore Circuits
}

\section{Dr. Theresa Mae Swift, Missouri University of Science \& Technology}

Theresa M. Swift is an Assistant Teaching Professor in the Department of Electrical and Computer Engineering at Missouri University of Science and Technology. She teaches the sophomore circuits and introduction to electronic devices courses for ECE majors as well as a service course in circuits for other engineering disciplines on campus. She is a member of both the ECE curriculum committee and the curriculum committee for all engineering disciplines on the Missouri S\&T campus. A member of both IEEE and ASEE, she is also a Past-Chair of the Midwest Section of ASEE.

\section{Mrs. Barbara Jean Wilkins, Missouri University of Science and Technology}

Barbara Wilkins is an Instructional Designer in Educational Technology at Missouri S\&T. She supports faculty in the effective use of technology in the classroom as well as blended/online course development. Barb has a B.A. in History with a Minor in Mathematics and an MST in Mathematics earned from the University of Missouri - Rolla, now Missouri S\&T. In addition to her work in Educational Technology, she teaches college algebra for the Missouri S\&T Department of Mathematics. Prior to joining S\&T, Barb taught in a local high school, East Central College, Drury University, and others. Barb has an interest in effective course redesign of STEM courses and gaming, and she has used her skills from both to aid the redesign of courses from across many disciplines. 


\title{
A Partial Flip, A Whole Transformation: Redesigning Sophomore Circuits
}

\begin{abstract}
In order to introduce more skill building and problem solving exercises into the Circuits curriculum, the second Circuits course, which focuses on circuits in the frequency domain, was redesigned into a partially flipped class model with group activities and group problem solving. Over the course of eighteen months, changes were implemented into the course, resulting in a fully redesigned course in early 2012. Since spring of 2013 all sections of the course have been taught using the new format including both a summer section and a distance section.
\end{abstract}

By placing review material online in an easy-to-reach location, students can review forgotten material from prior courses in a "just-in-time" fashion for some topics in the Circuits course curriculum. New material is also placed online and students are required to view this material before coming to class each day in order to be able to take part in group activities. This allows the students to review the new material repeatedly and to "pause" the instruction when they need more time to understand a concept.

Comparisons of in-class exam scores, between the new format and the traditional format, have shown positive results. Overall pass rates have been compared as well as end-of-course advancement exam scores. Student satisfaction survey data has been collected both from students at the end of the course and from graduating seniors who have taken the course in a prior semester.

By facilitating student-centered learning, students are showing at least equal if not increased success in the learning objectives. By requiring students to take ownership of their own learning, they are better prepared to continue in more advanced courses. The material remains available to students after they complete the Circuits course. This allows them to access it as a review for other courses such as Electronics and Power as well as for studying for the FE exam.

\section{Introduction}

A number of authors have published the results of their work on redesigning their classrooms and the learning experience for their students. Quite often this is done in upper level courses, introductory, or fundamentals courses. Each instance is different and is a product of the material being taught, the professor's comfort with and attitude toward the different methods, the number of students in the classroom, as well as the students' educational maturity level.

One method that is receiving a lot of attention is the inverted or flipped classroom. ${ }^{1,2,3,4}$ In the flipped classroom, the lecture content that is prevalent in most traditional classroom settings is moved out of the classroom through videos or readings. The face-to-face time with the professor is usually used for active learning exercises often in a group setting. The face-to-face time can also be reduced which is an advantage when classroom space is limited. 
The purpose of this paper is to describe the partially flipped redesign of the second Circuits course at Missouri University of Science and Technology (S\&T). This is a core course and is one of the foundational courses for both the Electrical and Computer Engineering curriculums. This is the one of the first steps in the redesign of several of the core courses in the Department of Electrical and Computer Engineering at S\&T.

\section{Motivation}

The second semester Circuits course at S\&T is focused primarily on AC circuits in the frequency domain. As with other sophomore courses in the Electrical and Computer Engineering courses on campus, the final exam is an advancement exam. Students are required to score at least a $\mathrm{C}$ or better on the advancement exam to pass the course. The course is heavily problem based and with the extensive use of complex numbers, students struggle.

The students at this level are just getting into the courses where material from prior courses is used and not "re-taught" when encountered. Many of the courses such as mathematics, physics, and chemistry are up to this point taught "in a bubble" with the application of material outside of the course largely ignored. The students are also still at the stage in their learning where they want a step-by-step process to follow for each problem and are resistant to the idea that there may be several ways to solve a particular problem. They want the professor to tell them how to work the problem and they will mimic that method ignoring all other possibilities.

In a traditional lecture course, the professor stands in front of a classroom and explains concepts, derives equations, and works examples for 50 or 75 minutes, often with little or no direct interaction with the students. With an attention span of about 15 minutes, students generally tune out and maybe tune back in when the examples are worked. For many, the examples are all they are interested in because all they are thinking about is working the homework. Their mindset is still that the course is a closed system. The two Circuits courses are the foundation of all other electrical engineering courses in the curriculum. Students must learn the concepts and understand them and not just mimic the professor's examples on the homework and exams.

With the traditional lecture format, students are presented with the new concepts and shown one or two examples, and then they are sent home to work out the homework problems. The actual learning in this model takes place during the homework. Often, these homework assignments are lengthy to order to insure that the concepts are covered completely. Students assume that if a concept or application is not important enough to be in the homework then it is not important enough to be on the test and thus can be ignored. Again, they are judging the importance of the material by the probability of it appearing as an exam question. The course is a closed system to them without applications outside of the course and the only requirement is to learn what is on the exam and pass the course.

With the Circuits courses at S\&T, the curriculum is strictly defined. The material to be covered is very specific and there can be little deviation. This also presents the problem of getting though all of the material in a timely fashion while trying to insure student understanding. There is simply not enough time to go back over material a second day if the students do not get it the 
first time. There is also no time in the schedule to bring in "real world" topics that show an application of the material to motivate the students.

A flipped model allows the student to learn the concepts prior to coming to class and to do so at their own pace. Rather than frantically copying notes while the professor lectures then trying to digest the material later while doing their homework, they see the concepts before coming to class in the form of short video lessons. The students can pause and rewind the video to go back over material which they did not understand the first, second, or even third time. Only the more aggressive students will stop a professor during a traditional lecture to ask questions and the time for such questions is limited by the class period. Also, it is quite possible that the student could have answered his or her own question given time to think about the material, but the traditional lecture goes at such a pace that there is often not enough time for the student to process the information.

\section{Course Redesign Goals}

The second Circuits course at S\&T was redesigned as a "partially-flipped" course. Part of the material that had been taught in the traditional lecture was recorded on short video lessons. About one third of the material was moved to video format.

The course was not totally inverted for several reasons. First was the professor's discomfort with switching immediately from lecture in front of a chalk board to "lecture" on video. Secondly, the students (and parents) have expressed dissatisfaction with what they see as the professor "not teaching" his or her classes when a large amount of the class is done outside of the actual classroom. They feel that they are paying for the professor's time and should get it. There is also the issue of student learning styles. Providing a variety of methods in which information is presented keeps the course fresh and engaging with the whole class rather than only the portion of the class whose learning style is being utilized.

The primary focus of the face-to-face time in the classroom is now on problem solving. With class sizes of 20 to 40 students, there can be significant interaction between the students and instructor that could not happen in the larger lectures. The students are also better prepared for class. Though the professor encourages the students to read their textbook before coming to class, few do so. Students are more receptive to short video lessons than textbook readings, particularly if those short videos can be reviewed on a mobile device.

Second, the course now only meets face-to-face twice a week for 50 minutes rather than three 50 minute lectures. The large increase in student numbers on campus and a lack of large lecture halls has meant that the smaller classrooms needed to be used more efficiently. By reducing the number of face-to-face hours, more classes can be scheduled into the same rooms during a given time period. This was a practical consideration but was of no less importance than finding a way to teach the students better.

The goal was to reduce the number of face-to-face hours while still giving the students an education that was at least as good as the traditional course. The hope was to do better than the traditional course by addressing several ideas including active and lifetime learning. 


\section{Class Structure}

The course was redesigned so that the students only met the professor face-to-face for two 50minute sessions per week rather than other original three sessions per week.

Online, prior to attending each face-to-face class:

- Students watch the short video lesson material for that day. (25 total)

○ Initially, a video was made available about a week before its due date. After the first semester, these were all available from the first day of class.

- Students take the online quiz over the video lesson. (24 total, there is no quiz for the first lesson)

- These are made available 5-7 days prior to due date and must be completed by 8 a.m. on the due date as this is the beginning of the first class. Due dates and times are the same for all sections even though some meet later in the day.

Face-to-face class:

- The professor provides a traditional lecture for material not covered in the video lessons (hence only a partially flipped design).

- The professor works examples on the board with particular attention paid to different methods for solving a particular problem. The students dictate how the problem is worked with the professor acting as a scribe and as a guide when they encounter difficulties.

- Group problems similar to exam and homework problems are worked in small groups (34 students) with a final solution turned in for each group and posted on Blackboard.

○ This is done eight times during the semester usually on the day that the material is finished for that topic.

- These problems are bonus for the $10 \%$ of the student's overall grade that consists of homework and the online quizzes and are worth the same points as an online quiz. Quizzes constitute approximately $20 \%$ of this homework/quiz grade with the remaining $80 \%$ coming from homework assignments.

- Topics include Mesh Current Analysis, Node Voltage Analysis, Superposition, Thévenin Equivalents, Single-Phase Complex Power, Transfer Functions and Simple Filters, Ideal Transformer Circuits, and Three-Phase Power Circuits.

- Three in-class exams are given over the material and constitute $60 \%$ of the students overall grade.

After the face-to-face class:

Students have a total of 20 homework assignments, approximately one for each face-toface class other than exam days and the day immediately following an exam. Two of these are dropped since late work is not accepted.

\section{Online Material}

The 25 video lessons were created using voice recordings over PowerPoint slides and a Wacom Bamboo tablet and recorded using Camtasia Studio. The Educational Technology group on campus then edited the videos, removing pauses and errors and adding closed captioning. The videos were between five and twelve minutes long to maximize student attention. Material that 
was considered conceptual, as well as all derivations, was covered in the videos. Some examples were also included and worked out step-by-step using the Wacom tablet to write on the PowerPoint slides. A screenshot from one of the videos is shown in Figure 1.

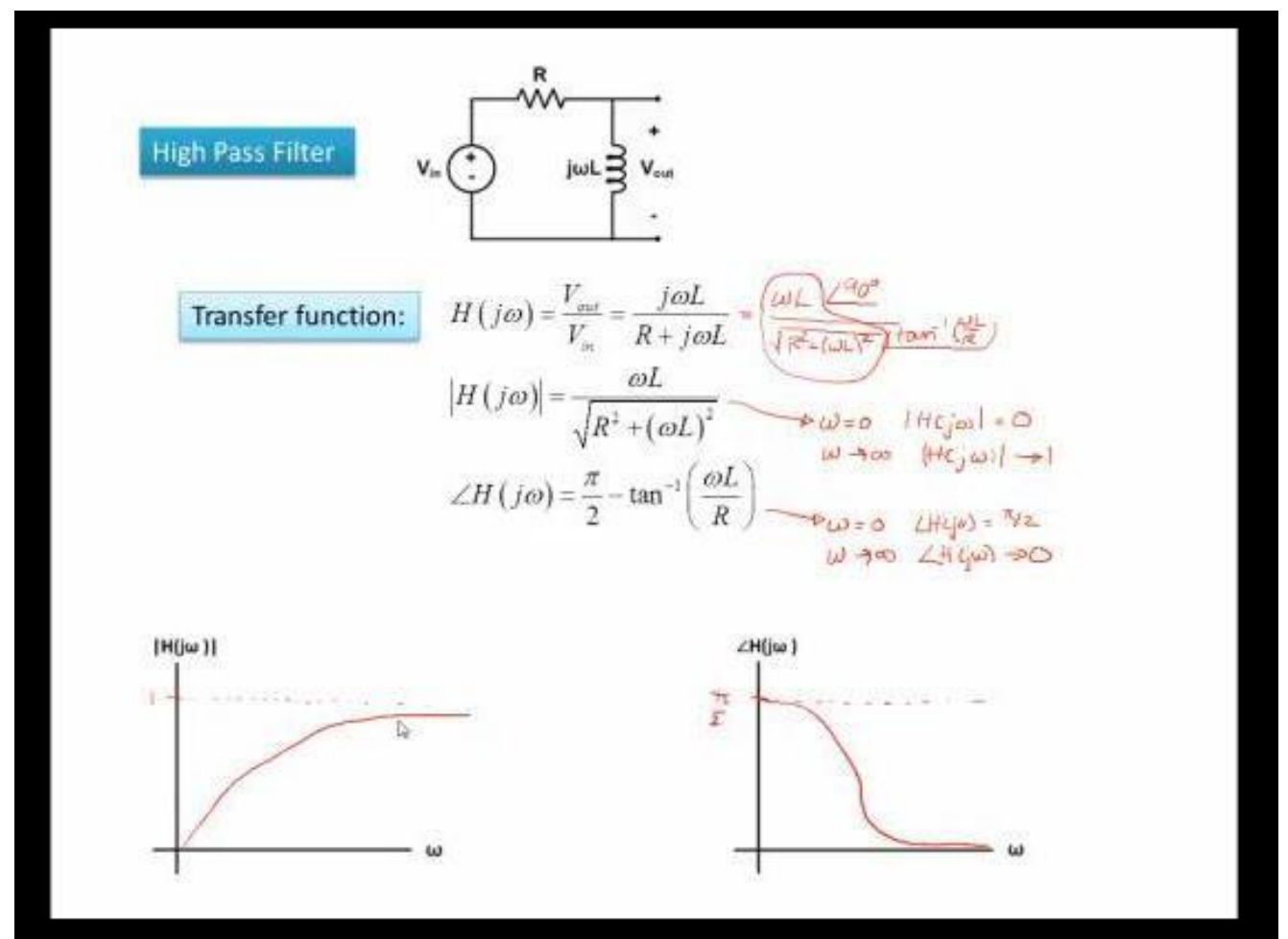

Figure 1: One Slide From the Frequency Response Video Lesson

The particular technology listed was chosen by the instructor and instructional designer due to technology available at the time the initial video lessons were created, as well as cost of technology. Current methods include not only the Wacom Intuos tablet, which replaced the Wacom Bamboo, but also tablet devices such as iPad and Android tablets, combined with apps such as Explain Everything. Camtasia Studio is still used for video editing due to the ease of use and cost. The instructional design team hires students to close caption instructor videos to meet the needs of both English Language Learners and The Americans with Disabilities Act. By being proactive, rather than reactive, the needs of all students are met and all students have benefited.

Another important consideration of the video lessons was length. The material in an engineering course of any kind is often difficult to condense, but preliminary studies ${ }^{5,6}$ have shown that shorter videos are better. There are many reasons for this, but in general, shorter videos are easier for the student to digest. They have an added bonus of allowing students to more easily navigate through content to find just what they are searching for when reviewing. In many cases, videos over 10 minutes simply are not watched all the way through, even though students understand that they are responsible for the content. With this in mind, each video lesson was planned to be as concise as possible. 
A short three or four question quiz covering the material in the video lesson was administered online through Blackboard. The students were required to watch a video lesson and take the quiz on that material before coming to class. Lessons were due at 8:00 a.m. since this is the beginning of classes at S\&T. This insured that students viewed the material before coming to class. In the pilot semester, students were allowed to drop two quizzes. In later semesters, none of the 24 quizzes were allowed to be dropped as an encouragement for students to watch and study the videos. An example of a quiz is shown in Figure 2.

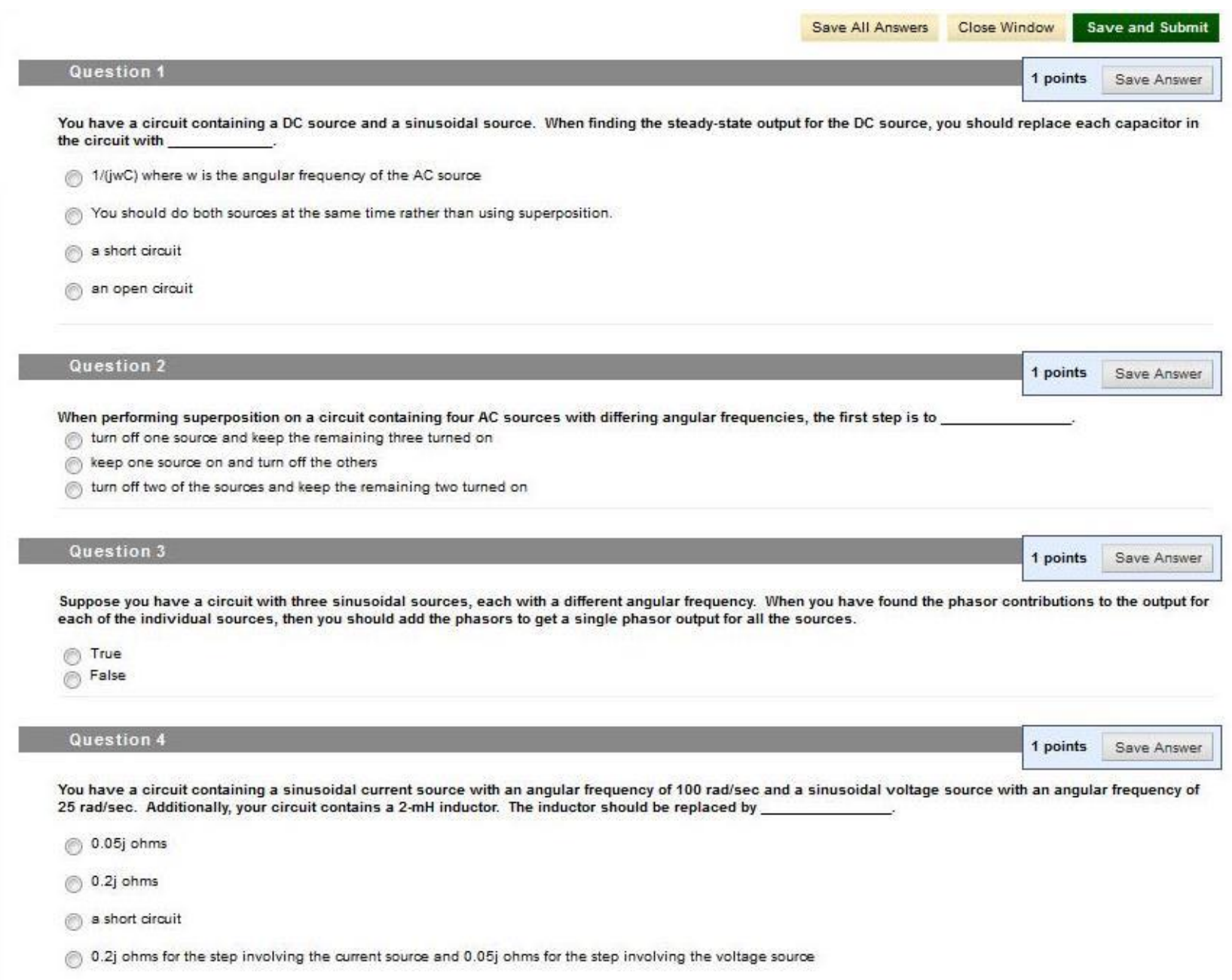

Figure 2: Example Quiz for the Superposition Video Lesson

It should be noted that online homework was not incorporated into the course design, only the short quizzes. While online homework was discussed, the decision was made that students would be better served by having their homework assignments manually graded. Since much of the focus of the class was on problem solving, the professor wanted to see the students' individual choices of solving method for the homework problems.

\section{In-Class Work}

The material that was covered in the face-to-face sessions included some traditional lecture but was primarily focused on solving problems by analyzing different techniques for circuit analysis. 
One of the most common issues students face is that they watch the professor work an example in front of the class and it looks easy, then they cannot determine where to start when confronted by a similar problem on their homework. Problem solving in class was conducted in a method were the students led the professor in finding the solution to the problem. First, possible techniques were listed by the students and then examined to determine which was the most efficient for that particular problem. The students then solved the problem on the board with the professor acting as a scribe and guide. The students were asked to justify why they could or could not apply certain techniques and why one would be preferable to another.

In-class group problems were added to compensate for missed quizzes and homework assignments. Eight class meetings were dedicated to students working in small groups of three or four to solve problems. This was generally done before homework was due on the particular subject. Thus there was less stress in the homework because many of the questions of how to approach a problem were sorted out prior to the assignment. The point of all of this was to make the material easier to learn. The students might not learn it "better" but they would learn it with less difficulty. Less homework could also be assigned because of the additional problems worked in class. Group work where there is only one problem given per group also encourages the students to actually discuss how to work the problem, double check each other, and to try to find the source of errors in their fellow student's work. When given a longer assignment to work on in a group, students will often divide up the material and assign smaller portions to each group member rather than looking at the assignment as a whole. While this is appropriate for a project-type problem, it was not the goal of the group work in this class.

\section{Results}

In Fall of 2011, the new course design was taught for the first time. Section A was taught with the partially-flipped design while sections B and $\mathrm{C}$ were taught in the traditional lecture format. Students met Mondays and Wednesdays for 50 minutes in section A and for 50 minutes Mondays, Wednesdays, and Fridays for sections B and C. Students received a daily schedule on the first day so they knew when each assignment was due.

Section A students were required to watch a video lecture before each class meeting. A short online quiz (through Blackboard) after each video lesson tested student understanding of the concepts covered in the lesson. During this pilot, the two videos were made available on Thursday afternoons and were due by 8:00 a.m., one on the following Monday and the other on Wednesday. The video lessons would remain up for the rest of the semester but the quizzes were taken down at 8:00 a.m. on their respective due dates. Section A met from 8:00 to 8:50 a.m., so the intention was that the students would be required to view the material before coming to class where the professor would emphasize applications of the concepts rather than derivations and theory. By having the video lessons and quizzes assigned after the Wednesday class and due before the Monday class, it was more readily apparent to observers that the online content actually replaced the Friday content, therefore the class still met the traditional time requirement.

Spring of 2012 was the second semester of the partially-flipped course. This time, both sections $\mathrm{A}$ and $\mathrm{B}$ were flipped while section $\mathrm{C}$ was taught as a traditional lecture. Section $\mathrm{C}$ did not originally have access to the video lectures but within the first few weeks of the semester asked 
to have access as well. A Google site was created so that all S\&T students could have access. This would also allow students to access the videos after they completed the course for as long as they were students at S\&T.

The blended courses also moved from Mondays and Wednesdays to Wednesdays and Fridays because the students did not like having exams on Mondays. The video lessons were all made available at the beginning of the semester rather than on a weekly basis. Only the online quizzes were activated on a weekly basis. Quizzes were made available on Friday afternoons and were then due on either Wednesday or Friday of the following week at 8:00 a.m. when the first classes began. Students were provided with a daily schedule which indicated the due date of each lesson, quiz, and homework assignment at the beginning of the semester.

Subsequent semesters, the professor moved all of their sections to the blended format as the student response was favorable and keeping some as traditional lecture courses did not seem to be necessary.

In Spring of 2013, the course was taught in the same format to a group of distance students at Missouri State University (MSU) through the Cooperative Engineering Program with S\&T. Through this program, students at MSU take courses both on the MSU campus and via live video feeds from S\&T. The ten students in the Spring 2013 course at MSU were taught using the same blended format as those at S\&T. This course is normally taught by a professor at MSU but due to illness was switched to a distance class shortly before the beginning of the semester.

The design was not as successful with the distance students due to limitations on the distance classroom. The "face-to-face" portion of the course did not allow as much student/professor interaction because the only microphone available to the students was at the front of the classroom. The students had to leave their seats and walk to the front of the classroom to ask the professor a question and the ability for the instructor to solicit student participation in the examples worked in class was practically nonexistent.

In 2013, the course was taught for the first time in the blended format in the eight week summer session. Students in the traditional summer session meet for five 60 minute lectures each week. The blended format allowed for the student to meet for only four 60 minute lectures each week giving the students Fridays off. There were no significant differences between the summer session and those during the regular semesters. The shortened time frame was not an issue.

\section{Test Results}

The advancement exam (final exam) and the three hourly exams were examined for a number of semesters (all for the same instructor) both in the traditional lecture format and in the partiallyflipped format. The mean exam scores for the eight most recent semesters in which the professor taught the course are shown in Figures 3 through 6 below. There did not seem to be a significant change in grades or pass rates. There was no apparent trend in the data. This may be partially due to the way in which the advancement exams are constructed. Many of the problems test a particular method of solving rather than leaving the method open to the student to choose. Part of this is to facilitate grading ease. It is also to insure that students know all the different 
methods taught in the course and have not merely picked their favorite and applied it to nearly everything. Reducing the face-to-face time has not negatively impacted the students' ability to learn the material and the blended format produces results at least equivalent to those of the traditional format.

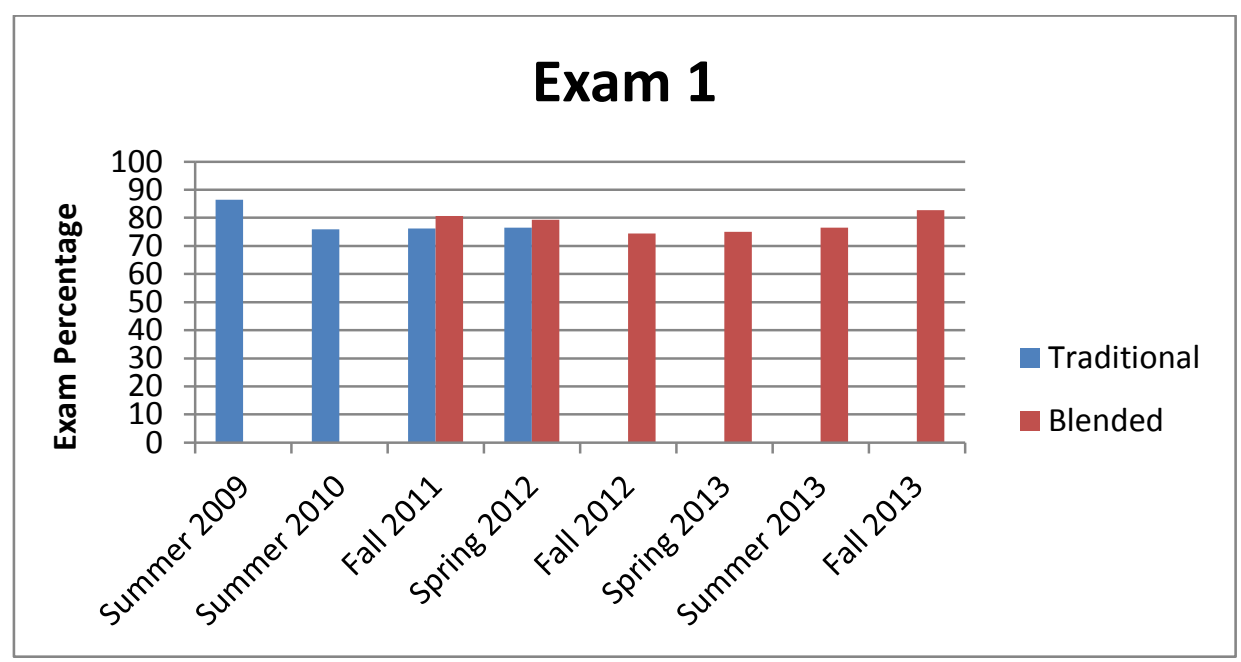

Figure 3: Exam 1 Means by Semester

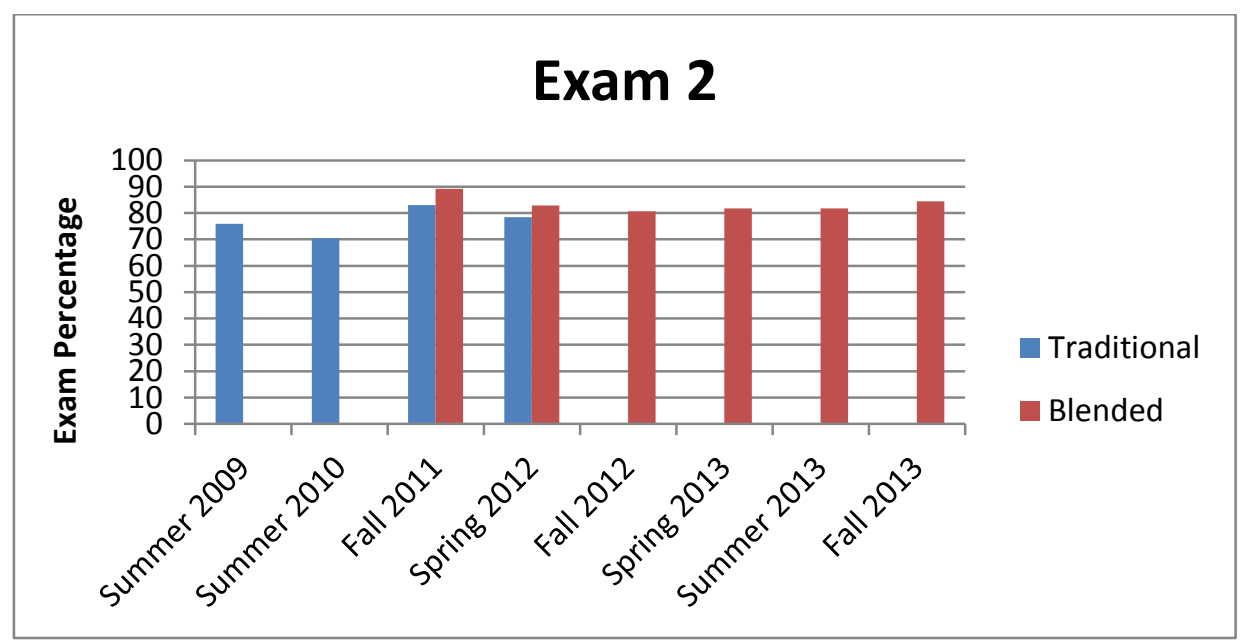

Figure 4: Exam 2 Means by Semester 


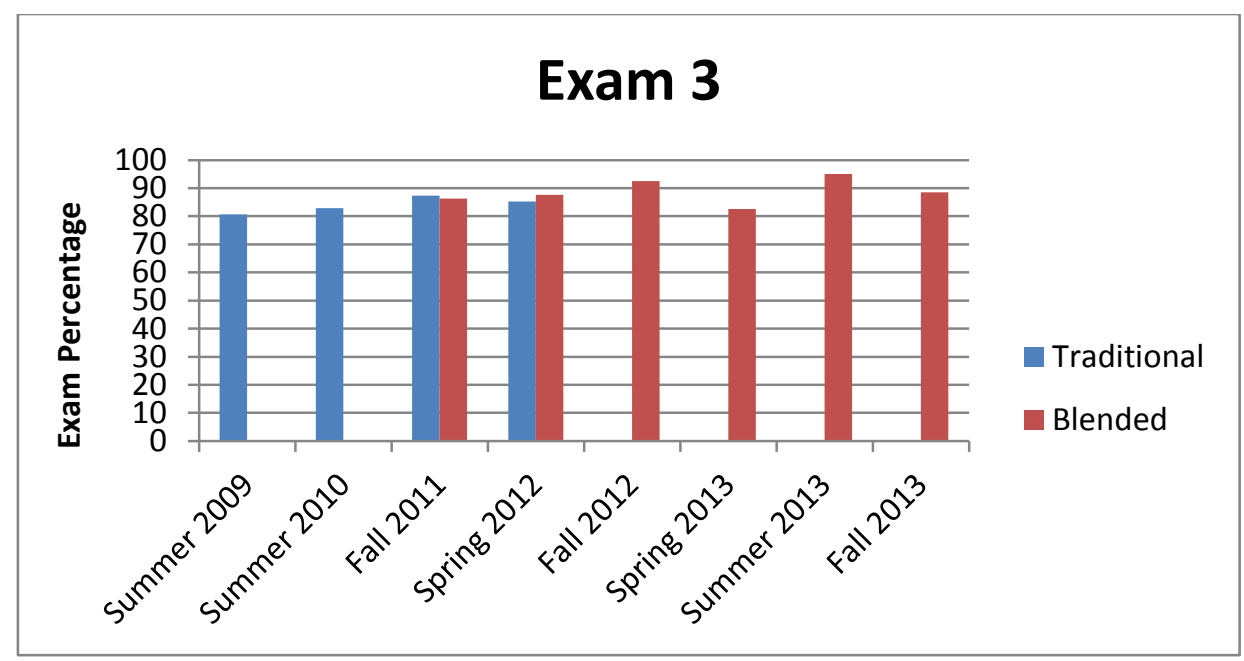

Figure 5: Exam 3 Means by Semester

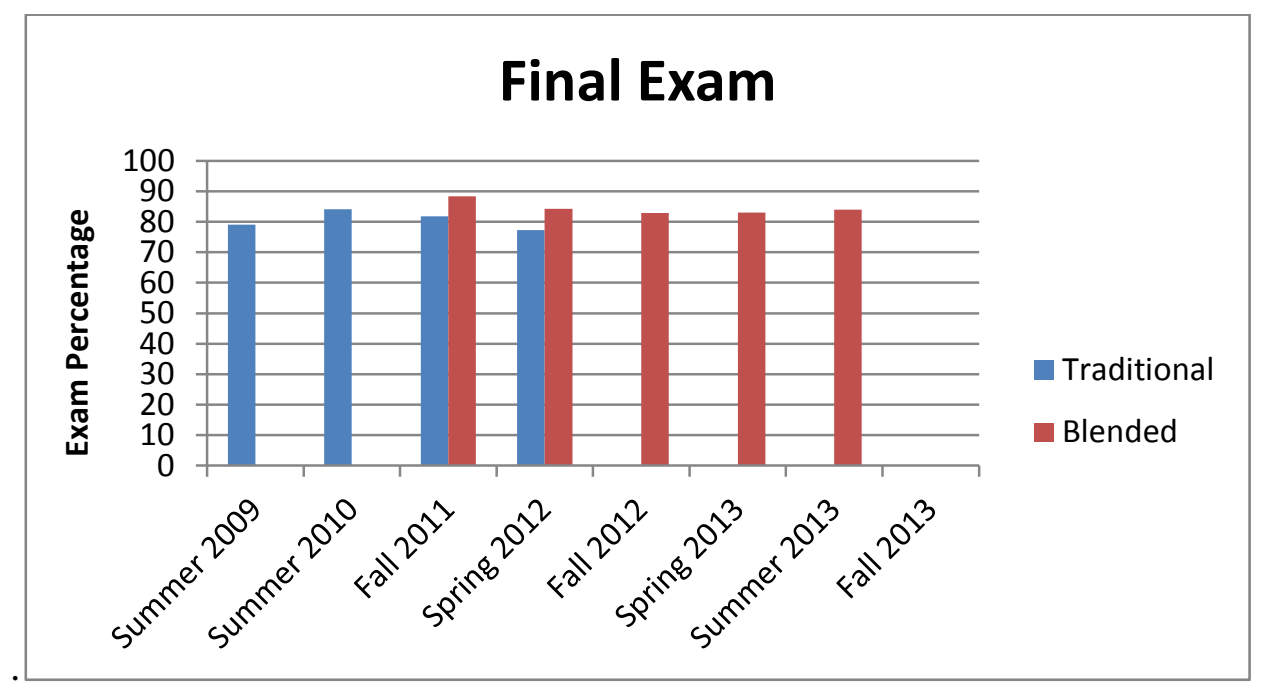

Figure 6: Final Exam Means by Semester

\section{Student Satisfaction}

Students were surveyed after the end of the pilot course in Fall of 2011 but response was minimal. What response was given was that they "liked" the videos. It was clear that the students had no frame of reference to answer questions other than that they "liked" or "disliked" the course. Some separation from the course and the taking other courses which use the material learned in the blended class was needed. Hence, a more extensive survey was given as part of the Senior Survey.

The Senior Survey is given to electrical and computer engineering students as part of their Senior Design course which is the capstone course for both majors. Fall of 2012 was the first semester that any students who had taken the blended class could have graduated. Data was collected in Fall of 2012 and Spring of 2013. Any student who took the second Circuits course in the blended format completed an additional thirteen questions. There were a total of 21 students who completed this part of the survey. The first nine questions are summarized in Table 1. 
Table 1: Senior Survey Data for Fall 2012 and Spring 2013 combined (21 students total)

\begin{tabular}{|c|c|c|c|c|c|}
\hline Survey Question & $\begin{array}{l}\text { Strongly } \\
\text { Disagree }\end{array}$ & Disagree & $\begin{array}{l}\text { Neither } \\
\text { Agree nor } \\
\text { Disagree }\end{array}$ & Agree & $\begin{array}{l}\text { Strongly } \\
\text { Agree }\end{array}$ \\
\hline $\begin{array}{l}\text { I would prefer that the course } \\
\text { be taught in a traditional } \\
\text { lecture. }\end{array}$ & 6 & 10 & 1 & 3 & 1 \\
\hline $\begin{array}{l}\text { The online material was easy } \\
\text { to access. }\end{array}$ & 2 & 0 & 1 & 4 & 14 \\
\hline $\begin{array}{l}\text { The blended format required } \\
\text { too much time outside of the } \\
\text { classroom. }\end{array}$ & 8 & 11 & 1 & 1 & 0 \\
\hline $\begin{array}{l}\text { I liked the format of the video } \\
\text { lessons. }\end{array}$ & 0 & 2 & 2 & 7 & 10 \\
\hline $\begin{array}{l}\text { Viewing the lessons before } \\
\text { coming to class helped in my } \\
\text { understanding of the material. }\end{array}$ & 0 & 2 & 1 & 7 & 11 \\
\hline $\begin{array}{l}\text { I think these lessons should be } \\
\text { available to all EE/CpE } \\
\text { students for reference in later } \\
\text { courses. }\end{array}$ & 1 & 0 & 1 & 11 & 8 \\
\hline \multirow[t]{2}{*}{$\begin{array}{l}\text { I would recommend this } \\
\text { course (in blended format) to } \\
\text { my friends. }\end{array}$} & 1 & 0 & 1 & 6 & 13 \\
\hline & Too Long & $\begin{array}{l}\text { About the } \\
\text { Right } \\
\text { Length }\end{array}$ & Too Brief & & \\
\hline \multirow[t]{2}{*}{ The video lessons were: } & 3 & 18 & 0 & & \\
\hline & $\begin{array}{l}\text { Learning } \\
\text { New } \\
\text { Material } \\
\end{array}$ & $\begin{array}{l}\text { Studying } \\
\text { for the } \\
\text { Exam } \\
\end{array}$ & Homework & Other & \\
\hline $\begin{array}{l}\text { I have used the video lessons } \\
\text { for: (Choose all that apply) }\end{array}$ & 18 & 12 & 17 & 0 & \\
\hline
\end{tabular}

The remaining four questions were free response questions and not all 21 students provided answers to all the questions. These are summarized below:

Question 10: What other material would you like to have seen covered in the video lessons?

- Nothing (10 responses)

- I think the videos were the perfect length with just the right amount of content. It might have been neat to see some real-world applications in a sort of "How It's Made" format but that might be going a bit over the top. 
- All material. Use the Internet more. Try to experiment and innovate with new approaches.

Question 11: What are the positive aspects of taking Circuits II as a blended course?

- I don't know. (3 responses)

- It made it easier to refer back to a particular lecture if you were weak in any one area.

- Allows for more time during lecture periods to work out examples while the student is able to learn the theory online first and then ask questions later in class.

- Schedule flexibility. The videos serve as a great memory aid and can be viewed in a more relaxed environment. Videos can be repeated.

- Re-watching videos if you didn't understand the material the first time around.

- Seeing the information before the lecture

- Exposure, convenience, custom pacing.

- Seemed to have an understanding of topics before entering the classroom which helped.

- The videos were better than having notes because you had the lecture along with the notes so you did not miss the little things that were said that you sometimes miss while taking notes.

Question 12: What are the negative aspects of taking Circuits II as a blended course?

- None (8 responses)

- Both in-class and online assignments

- More outside work

- Less time in class to ask questions

The final question was asked with the intention of seeing which classes the students would like to see taught as a blended or partially-flipped class.

Question 13: What other EE/CpE courses do you think should be taught as a blended course (if any)?

The result was a list of all the sophomore electrical and computer engineering classes plus several at the junior level including electromagnetics, power, and linear systems courses. Additionally, two students said "as many as possible" and two more thought all of them should have been taught blended. One of the students summed up the whole idea behind flipped classrooms. The student's response was: "All of them. I would love lectures online, and more practical application, real world problem solving during class time. Use class time for teacherstudent interaction, not one directional dictation."

\section{Conclusion}

The implementation of a partially-flipped design to the second Sophomore Circuits course at S\&T was successful in fulfilling its goals. The student success in the course, as defined by their success on the advancement exam, was not negatively impacted by switching to the blended format. Student satisfaction was high with the results of the Senior Survey indicating that the majority of students not only liked the format but would have liked to have other courses in the curriculum adopt a similar format. 
Currently, several other courses in the Electrical and Computer Engineering curriculum at S\&T are being converted over to a partially-flipped format. One course currently under redesign is a four-hour lecture course in Electromagnetics. The four-hour per week meeting has caused scheduling issues for the department and is one of the primary reasons for the course's redesign to a three-hour lecture with at least a fourth of the material moved online. There is also the possibility that some of the material that was cut when the course was changed from two threehour courses to a single four-hour course could be brought back and covered in the video lectures as there is not time in the current face-to-face lecture.

Professors are always limited by the number of hours they have in the classroom. To be able to move traditional lecture topics to video lessons which the students watch before coming to class, allows the professor to delve more deeply into a topic and show more applications of the theories taught. Students at nearly all levels ask the same question: Why am I learning this? By bringing more applications to the classroom and getting students involved in the learning process, we can give the students the skills they need to learn throughout their lifetimes. Engineering is constantly changing and an engineer never stops learning. Part of our job as educators is to teach students how to learn on their own, because there will not always be a professor to explain it.

\section{Bibliography}

1. B. Morin, K. M. Kecskemety, K. A. Harper, P. A. Clingan, "The Inverted Classroom in a First-Year Engineering Course,” $120^{\text {th }}$ ASEE Conference \& Exposition, June 23-26, 2013, Atlanta.

2. R. H. Rockland, L. Hirsch, L. Burr-Alexander, J. D. Carpinelli, H. S. Kimmel, "Learning outside the classroom - Flipping an Undergraduate Circuits Analysis Course," $120^{\text {th }}$ ASEE Conference \& Exposition, June 23-26, 2013, Atlanta.

3. G. S. Mason, T. R. Shuman, K. E. Cook, "Comparing the Effectiveness of an Inverted Classroom to a Traditional Classroom in an Upper-Division Engineering Course," IEEE Transactions on Education, Vol. 56, No. 4, November 2013.

4. F. Alonso, D. Manrique, L. Martínez, J. Viñes, "How Blended Learning Reduces Underachievement in Higher Education: An Experience in Teaching Compute Sciences," IEEE Transactions on Education, Vol. 54, No. 3, August 2011.

5. C. Savage, B. Ruedlinger, "Does Length Matter? It Does For Video: 2K12 Edition" Wistia.com, Retrieved January 3, 2014, http://wistia.com/blog/does-length-matter-it-doesfor-video-2k12-edition/

6. P. Guo, "Optimal Video Length for Student Engagement”, www.edx.org, Retrieved January 3, 2014, https://www.edx.org/blog/optimal-video-length-student-engagement 